\title{
Ortak Yöntem Yanlılığı Üzerine Sistematik Bir Yazın Taraması
}

\author{
A Systematic Review of Common Method Bias
}

\author{
Beykan ÇizEL*, Onur SELÇUK**, Eniser ATABAY*** \\ * Prof. Dr., Akdeniz Üniversitesi Yerleşkesi, Turizm Fakültesi, Dumlupınar Bulvarı, 07058, Konyaaltı, Antalya. \\ E-posta: beykan@akdeniz.edu.tr \\ ORCID:0000-0003-0474-9222 \\ ** (Sorumlu Yazar) Araş. Gör., Akdeniz Üniversitesi Yerleşkesi, Turizm Fakültesi, Dumlupınar Bulvarı, 07058, Konyaaltı, Antalya. \\ E-posta: onurselcuk@akdeniz.edu.tr \\ ORCID:0000-0003-2818-2291 \\ *** Öğr. Gör., Akdeniz Üniversitesi, Göynük Mutfak Sanatları Meslek Yüksekokulu, Cumhuriyet Mahallesi 136. Sokak No: 7, 07994, Göynük, Kemer, Antalya. \\ E-posta: eniseratabay@akdeniz.edu.tr \\ ORCID:0000-0001-8481-1086
}

MAKALE BILGILERI

Makale işlem bilgileri:

Gönderilme tarihi: 16 Eylül 2019

Düzeltme: 13 Aralık 2019

Kabul: 19 Aralık 2019

Anahtar sözcükler: Turizm araştırmaları, Ortak yöntem varyansı, Ortak yöntem yanlılığı, Bibliyometri, $R$ programi.

\section{ARTICLE INFO}

Article history:

Submitted: 16 September 2019

Resubmitted: 13 December 2019

Accepted: 19 December 2019

Key words: Tourism research,

Common method variance, Common method bias, Bibliometry, $R$ program.

\section{$\ddot{O Z Z}$}

Bu makalenin temel amacı, ortak yöntem yanlılığının ne olduğunu, önemi, olası nedenlerini ve yanlılığı kontrol etmenin yollarını açıklamak ve turizm araştırmalarındaki mevcut durumun tespitini yapmaktır. Bu amaç doğrultusunda karma yöntem ile sistematik yazın taraması gerçekleştirilmiştir. İlk olarak Scopus'ta yayımlanan anahtar kelime ve özetlerinde yöntem yanlılığı, ortak yöntem yanlılığı (OYY) ve ortak yöntem varyansı (OYV) kelimeleri geçen toplam 1534 çalışma, "R" programı ile bibliyometrik yöntemler kullanılarak analiz edilmiştir. İkinci aşamada manuel olarak, saptanan temel kaynaklar üzerinden yöntem yanlılığının olası nedenleri ve kontrol etme yolları incelenmiştir. Son olarak ise OYY'nin olası nedenleri ve kontrol etme yöntemleri ile ilgili ölçüt seti olușturulmuș ve 1534 çalıșmanın içerisinde turizm dergilerinde yayımlanan 19 çalıșma değerlendirilmiştir. Yazın taraması sonuçları uluslararası turizm dergilerinde araştırmacılar arasında oYY konusunda az da olsa bir farkındalık oluştuğunu göstermektedir.

\section{ABSTRACT}

The main aim of this paper is to explain the common method bias (CMB), its importance, possible causes and ways to control it. Additionaly, the current situation of CMB in tourism researches has been examined on the basis of the articles. For this purpose, systematic literatüre review was conducted with mixed method. Firstly, a total of 1534 articles related with CMB published in SCOPUS were analyzed using bibliometric methods with ile "R" program. Secondly, the possible causes of CMB and ways of controlling them were examined manually through the main sources determined by bibliometry. Finally, 19 articles published in tourism journals were examined with determined criteria to present the current awareness of CMB. The results of the literatüre review show that there is little awareness among researchers in international tourism journals.

\section{GiRiş}

Hata, gerçek değerle ölçülen değer arasındaki farklılıktır. Matematiksel modeller analitik ' 0 ' hatalı çözümler üretirken, gerçek yaşamdan elde edilen veriler hata içerir. Bu tür veriler için kullanılan modeller ise olasılıklı istatistiksel modellerdir. İlgili yazında iki türlü hatadan söz edilir; bunlardan ilki, rastgele (random) hatalardır. Bu hatalar, ölçme işlemini yapan kişiden kaynaklandığ 1 için ölçme işleminin doğasında olan bir durumdur ve istatistiksel kestirimler bu hatalardan yararlanır. İkinci hata ise sistematik hata olarak adlandırılır. Ölçümlere karışan sistematik hatalara yanlılık (bias) adı verilir (Campbell ve Fiske 1959). Bu hata ölçme aracından kaynaklanır ve istatistiksel modellerin yanlış kestirilmelerine yol 
açar. Ölçmelere sistematik hata karışıyorsa öncelikle bunun tespitinin yapılması ve sonrasinda ölçme aracının iyileştirilmesi gerekir. Modelde temsil edilmeyen değişkenler, güvenilirliğin bir sorunu iken modelde yer alması istenmediği halde bir şekilde modele karışan değişkenler ise geçerliliğin bir sorunudur. Psikometride ölçme ve değerlendirme kapsamında yapılan çalışmalarda rastgele hatanın varlığını araştırmak bir güvenilirlik çalışmasıdır. Sistematik hatanın varlığı$\mathrm{n} ı$ araştırmak ise yanlılık araştırmasıdır. Her iki hata türü de ölçme aracının geçerliliğini azaltır. Ancak sistematik hata, özellikle yapı geçerliliğini olumsuz yönde etkilemektedir (Podsakoff vd. 2003).

Son yıllarda, psikoloji ve organizasyon çalı̧̧maları içindeki görgül araştırmalar, ortak yöntem varyansı (OYV) kavramına büyük önem vermektedir. Richardson, Simmering ve Sturman (2009) ortak yöntem varyansını "aynı yöntem ve / veya kaynağın bir işlevi olarak ölçülen ve sunulan değişkenler arasında paylaşılan sistematik hata varyansı" olarak tanımlamaktadır. Sistematik hata varyansı, ölçütler arasındaki tahmini ilişkileri önleyebilir (Campbell ve Fiske 1959) ve ölçüm yanlılığına neden olabilir. İki değişken arasındaki tahmini ilişkide yanlılık olması durumunda ortak yöntem, her iki temel değişkeni de sistematik bir şekilde etkileyen kafa karıştırıcı (veya üçüncü) bir değişken olarak düşünülebilir. Bu durum, ilgili temel değişkenler arasındaki gözlenen ilişkiyi şişirebilir, azaltabilir ya da ortadan kaldırabilir.

Turizm araştırmalarında bağımsız ve bağımlı değişkenleri ölçmek için sıklıkla ölçüm araçları kullanılmaktadır. Araştırmacılar, anketlerle toplanan verilerde bir değişkenin bir başkası üzerindeki tahmini etkisini değerlendirmede ortak yöntem varyansının (Common Method Variance) kontrol edilmesini önerirler. Bunun sebebi değişkenler arasında paylaşılan sistematik varyans, teorik yapılar yerine ölçüm yöntemiyle yapılan ölçümlere dayanabilir (Podsakoff vd. 2003; Podsakoff vd. 2012). Örneğin, turistlerin bir destinasyon ile ilgili memnuniyetinin sadakat üzerindeki algılanan etkisi incelendiğinde iki değişken arasında ölçülen korelasyon, ölçümlerin toplandığg 1 ortam, ifadelerin ölçüm aracındaki yerleri, soruların özellikleri, verilerin toplandığı kaynak ve katılımcıların özellikleri gibi nedenlerden dolayı ortak yöntem yanlılığından (Common Method Bias) etkilenmiş olabilir.

Bu çalışma ulusal turizm yazınında ortak yöntem yanlılığı konusundaki farkındalığ 1 arttırma niyeti taşımaktadır. Bu amaçla çalışmada sistematik yazın taraması yapılmıştır. Öncelikle nicel olarak R programı kullanılarak Scopus'ta yayımlanan ve anahtar kelime, başlık ve özetlerinde Ortak Yöntem Yanlılı̆g (OYY) ve Ortak Yöntem Varyansı (OYV) kelimeleri geçen toplam 1534 çalışma analiz edilmiştir. Sonrasında araştırmacılar tarafından OYY'nin ne olduğu, önemi, olası nedenleri ve yanlılığı kontrol etmenin yolları alan yazındaki temel kaynaklar üzerinden tespit edilmiştir. Son olarak ise OYY nedenleri ve kontrol etme yöntemleri ile ilgili ölçüt seti kullanılarak 1534 çalışma içerisinde turizm dergilerinde yayımlanan 19 çalışma incelenmiş ve mevcut durum değerlendirilmiştir. Araştırma sonuçları uluslararası turizm yazınında OYY konusunda artan bir farkındalığın olduğunu ortaya koymaktadır. Ulusal yazında da benzer farkındalığın artmasının araştırma sonuçlarının geçerliliği ve güvenilirliğini artıracağı öngörülmektedir.

\section{YAZIN TARAMASI}

OYY'nin bilimsel araştırmalardaki etkisinin tartışmaları yaklaşık 50 yıldan daha öncesine dayanmaktadır. İlk olarak Campbell ve Fiske (1959), bu sorunun psikoloji alan yazınında var olduğunu ileri sürmüş, ilerleyen süreçte tüm sosyal bilimlerde tartışma konusu olmuştur (Podsakoff vd. 2003; Spector 2006; MacKenzie ve Podsakoff 2012; Min vd. 2016).

İnsan davranışlarına odaklanan pek çok çalışma, katılımcının içinde bulduğu farklı durumlarla ilgili tutumlarını, algılarını ve inançlarını anlamaya yöneliktir. OYY, bu tür tutum-davranış, inanç-davranış, alg1-davranış konulu ilişkileri araştıran görgül çalışmalarda verinin aynı kişiden, aynı zamanda ve aynı yöntemle toplanması sonucu oluşmaktadır. OYY, değişkenler arasindaki var olan korelasyonu olduğundan daha fazla ya da az gösterebilmektedir (Podsakoff vd. 
2003; Richardson vd. 2009; Conway ve Lance 2010; Podsakoff vd. 2012). Richardson vd. (2009), OYV'yi “aynı yöntemin ve/veya kaynağın bir fonksiyonu olarak sunulan değişkenler arasında paylaşılan sistematik hata varyansı olarak tanımlanmaktadır. Bagozzi ve Yi (1991), sistematik ölçüm hatalarının ana kaynaklarından birinin, çeşitli nedenlerden kaynaklanabilecek yöntem varyansı olduğunu belirtmiştir. Yöntem varyansı, ölçme hatasının temel kaynaklarından biri olduğu için özellikle davranışla ilgili araştırmalarda problem oluşturmaktadır (Podsakoff vd. 2003; Podsakoff vd. 2012).

Yöntem varyansı, sistematik ölçme hatasının temel nedenlerinden biri olarak kabul edilmektedir. Sistematik hata varyans1, potansiyel olarak yanıltıcı sonuçlara neden olacak şekilde, görgül araştırma sonuçları üzerinde ciddi bir etki yaratabilmektedir (Campbell ve Fiske 1959). Oluşan bu sistematik hata, değişkenler arasındaki ilişkilerin ortaya çıkmasını engellemekte ve ilişkinin kuvvetini aşırı şekilde arttırabilmekte veya azaltabilmektedir (Podsakoff vd. 2003; Spector 2006; Conway ve Lance 2010). Bu durum görgül araştırmalarda iki önemli olumsuz etki yaratmaktadır. İlki OYY'nin oluştuğu çalışmalarda gerçekte var olan hipotez ilişkinin yokmuş gibi kabul edilmesine yol açabilmektedir. Bu nedenle OYY, araştırmanın hipotez kabulünde gerçekte var olan korelasyondan farklı bir gözlenmiş korelasyon oluşturması nedeniyle Tip I ve Tip II hatanın oluşmasına sebep olmaktadır (Podsakoff vd. 2003). OYY'nin ikinci olumsuz etkisi ise yapı güvenilirliği ve geçerliliği ölçümlerini saptırmasıdir (Williams vd.2010). Sistematik hata varyansı kontrol edilmezse bu varyans yapidaki sistematik değişken ile birlikte toplanacaktır. Bu da ölçeğin güvenilirliği ve yapı geçerliliğinin yeterliliği konusunda hatalı algılara yol açabilecektir (Lance vd. 2010). Podsakoff vd. (2012) ve Williams vd. (2010) bu durumun bir ölçeğin, olmadığı halde, güvenilir ve örtüşme geçerliliği olan bir ölçekmiş gibi algılanmasına yol açabileceğini ifade etmektedir.

\section{YÖNTEM}

OYY konusu ile ilgili alanı etkileyen çalışma, yazar, dergi ve eğilimlerin belirlenmesi için önce- likle sistematik analiz yöntemlerinden biri olan bibliyometrik analizden yararlanılmıştır. Bibliyometrik analizler alanı etkileyen çalışma, yazar, dergi ve eğilimlerin tanımlanmasına ve aralarındaki ilişkilerin ortaya çıkmasına izin verdiği için önemlidir. Bibliyometrik analiz, araştırmacıların ele aldıkları konuyu konumlandırmaları ve sınırlarını görmelerine imkân tanır (Ferreira 2018). Bu çalışmada analiz için R programı, görselleştirmeler için VOSviewer kullanılmıştır. Araştırmanın ikinci aşamasında bibliyometrik analiz sonucunda tespit edilen temel çalışmalar araştırmacılar tarafından analiz edilmiştir. Bu aşamada yöntem yanlılığının ne olduğu, olası nedenleri ve yanlılığı kontrol etmenin yolları betimlenmiş ve ölçüt kriterleri listelenmiştir. Araştırmanın son aşamasinda ise incelenen 1534 çalışmadan uluslararası turizm dergilerinde yayımlanan 19 çalışma OYY ölçüt kriterleri ile incelenmiş ve turizm dergilerindeki OYY ile ilgili mevcut durum değerlendirilmiştir. OYY alanında yapılan çalışmaları tespit etmek için Scopus veri tabanında "common method bias", "method bias", "common variance", "method variance" kelimelerinin geçtiği İngilizce içerikler (başlık, özet, anahtar kelime) değerlendirme kapsamına alınmıştır. Verilerin tek bir sonuç listesinde toplanması için aşağıdaki arama parametresi kullanılmıştır.

(TITLE-ABS-KEY ("common method bias" OR "method bias" OR "common method variance" OR "method variance")) AND (LIMIT-TO (LANGUAGE, "English"))

Bu kapsamda 1534 adet çalışma bulunmuş ve çalışmalar en çok atıf yapılandan geriye doğru sıralanarak ris ve csv formatlarında indirilmiştir. Ris formatı R'da kullanılan bibliometrix (Aria ve Cuccurullo 2017) paket aracılığıyla programa okutulmuş, csv formatlı dosya ise VOSviewer programına yüklenmiştir. R programı esnek yapısı ve zengin paketleri ile araştırmacıların gereksinimlerini karşılama bağlamında birçok seçenek sunma yetisine sahiptir. Bibliometrix paketi, bibliyometri analizleri yapmak için geliştirilmiş hızlı ve çok yönlü çözümleri olan bir eklentidir. Bu paket sayesinde eser, yazar, dergi ve kuruluşlar hakkında nicel veriler; eş-dizimlilik, 
eş-yazarlık, atıf, birlikte-atıf ağları; eğilim, faktör ve tema analizleri; birliktelik analizleri, haritalarr elde edilebilmektedir. VOSviewer ise R istatistik programına nazaran görselleştirme üzerine daha çok odaklanmış bir yazılımdır. Bibliometrix paketine benzer bir şekilde eş-dizimlilik, eşyazarlık, atıf, birlikte-atıf ağlarını görselleştirmek ve birliktelik analizleri yapmak mümkündür. Ayrıca özet, anahtar kelime ve çalışma başlıklarını derleyerek metin madenciliği kapsamında eği$\mathrm{lim} /$ trend analizi de yapabilmektedir (Van Eck ve Waltman 2010).

\section{BULGULAR}

\section{Bibliyometrik Analiz Sonuçları}

1962 ile 2019 yılları arası OYY ile ilgili 1534 adet çalışmanın 850 farklı kaynakta yayınlandığı saptanmıştır. OYY konulu çalışmalar birlikte atıf alma analizi ile incelendiğinde, çalışmaların kaynakçalarında sıklıkla yer alan "Podsakoff"ların ağ yapisında merkezi bir konuma sahip oldukları dikkat çekmektedir. Alanda "P.M. Podsakoff" ve "N.P. Podsakoff" un önemli ağırlıklarının olduğu görülmektedir (Şekil 1).

Eş-dizimlilik ă̆ analizi, kelimelerin birlikte geçme durumunun görselleştirmesine dayanmaktadır. A ̆g üzerinde yer alan büyük daireler, hangi terimlerin daha sık kullanıldığını; birbirine daha yakın ve aynı renge sahip olan terimler ise hangi terimlerin birlikte daha sık ortaya çıtığını göstermektedir. VOSviewer, eş dizimlilik analizi yaparken yoğunluk haritası oluşturmaya da imkân tanımaktadır. OYY alanında yazılmış çalışmaların anahtar kelimelerinin birlikte geçme ve kümelenme durumlarını gösteren harita Şekil 2'de yer almaktadır. Bu ağ analizi OYY alanında yapılmış çalı̧̧maları uzak bir çerçeveden inceleyip genel bir görüş elde etmenin en iyi yöntemlerinden biridir. Bu yönteme göre şekil incelendiğinde kırmızı kümede yer alan terimlerin daha çok yöntem yanlılıkları ve istatistik alanıyla ilgili olduğu, mavi ve yeşil kümelerin yönetim ve insan kaynakları alanını kapsadığı, turuncu ve mor kümelerin ise psikoloji, sosyoloji vb. konularında çalışmaları içerdiği görülmektedir.

Dönemsel doğrudan atıf analizi alanın gelişimini gösteren önemli analizlerden biridir. $\mathrm{R}$ istatistik programında yer alan bibliometrix kütüphanesi hangi çalışmanın hangi çalışmaları yıllar içerisinde etkilediğine dair bir zaman çizelgesi oluşturmaktadır. Şekil 3'te yer alan doğrudan atıf zaman çizelgesi incelendiğinde Podsakoff (1986), Bogazzi (1990) gibi yazarların yapmış olduğu yayınların yıllar sonra bile diğer yazarları çok fazla etkileyebildiği söylenebilir.

OYY konusunda alan yazına önemli katkısı olan birçok kaynak mevcuttur. Veri tabanında toplam 850 adet dergi yer almaktadır. Tablo 1'de yer alan yayınlar incelendiğinde Journal of $\mathrm{Ma}$ -

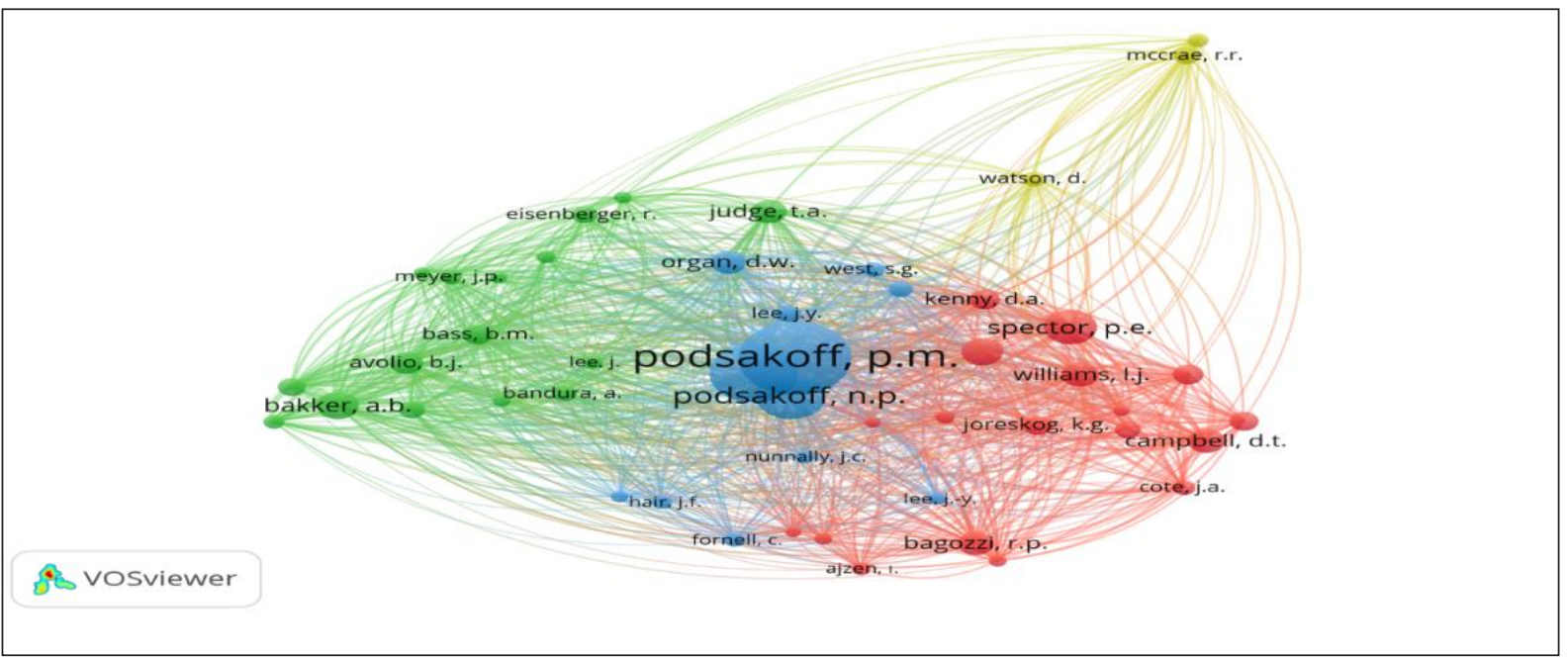

Şekil 1. Birlikte Atıf Analizi 


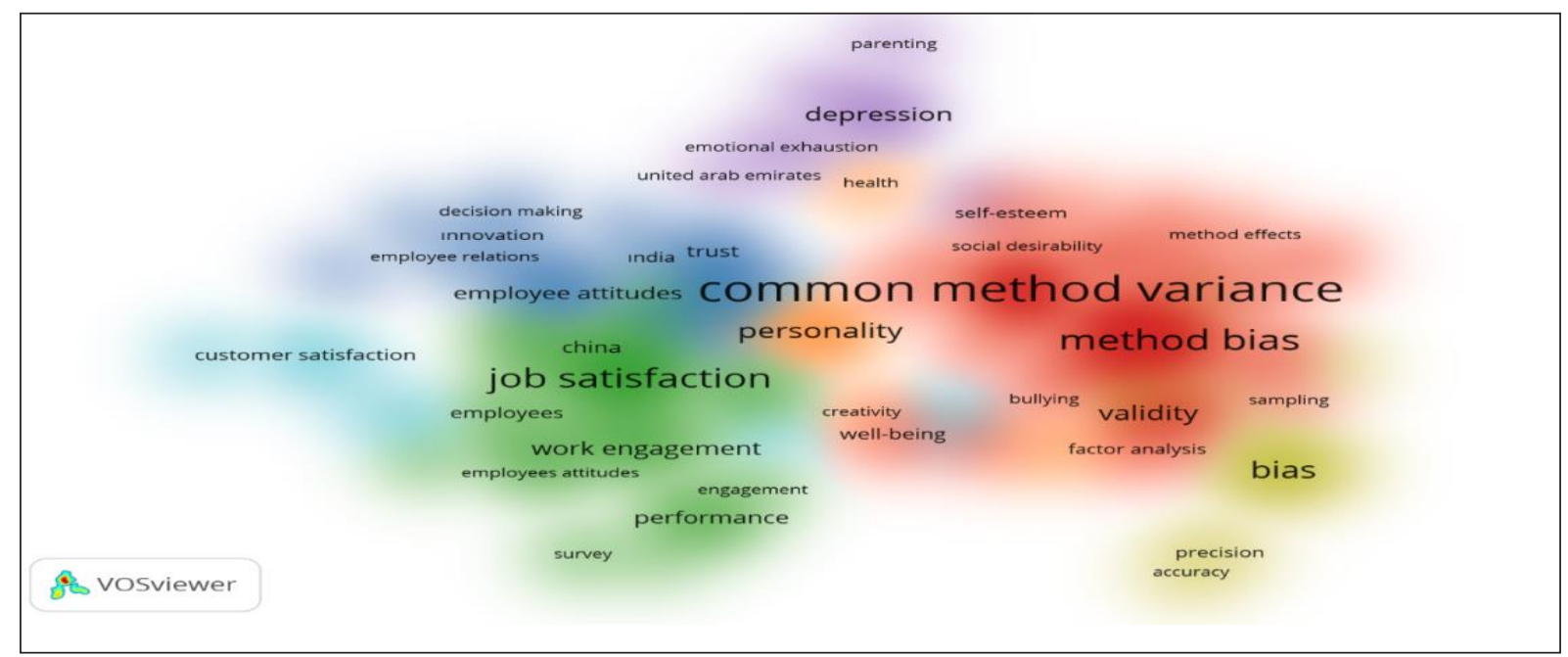

Şekil 2. Eş-Dizimlilik A ̆̆ Analizi

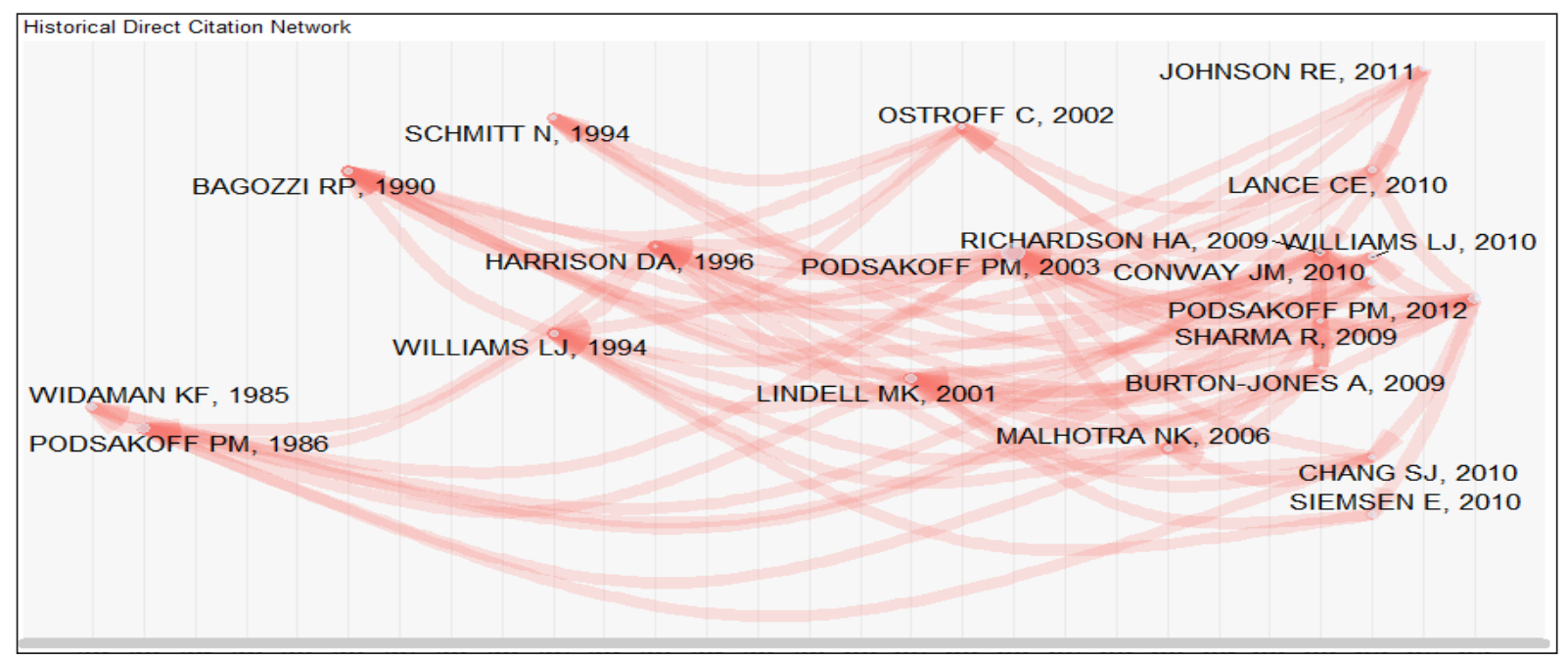

Şekil 3. Doğrudan Atıf Zaman Çizelgesi

nagerial Psychology, Leadership and Organizational Development Journal, Journal of Applied Psychology gibi dergiler, ilk üç sırada yer almaktadır. Toplam atıf alma sayısında öne çıkan dergiler ise Journal of Applied Psychology (28030), Journal of Management (8705), Organizational Research Methods (5039) dergileridir. Bu dergilerin arasına turizm dergilerinden yalnizca International Journal of Contemporary Hospitality Management (225) dergisi girmiş̧ir.

Buraya kadar bibliyometrik analiz ile OYY çalışmalarının entelektüel yapısı ortaya konmuştur. Araştırmanın ikinci kısmında alanda öne çı- kan makalelerin içeriği analiz edilerek OYY'nin nedenleri, ontrol edilmesinde prosedürel çareler ve istatistiksel çözümler ortaya konmuştur.

\section{Ortak Yöntem Yanlılığının Nedenleri}

OYY araştırma bulgularını çarpitabileceğinden, olası hata kaynaklarını ve ortaya çıkması muhtemel koşulları anlamak önemlidir. OYY'nin ortaya çıkmasının nedenleri dört grupta toplanmaktadır. Bunlar: (1) bağımlı ve bağımsız değişkenlere ait verilerin ayn kaynaktan veya katılımcıdan toplanması, (2) araştırma değişkenlerini ölçmede kullanılan ifadelerin veya soruların kendi özellikleri, (3) ifadelerin anketteki yerleri, (4) ölçüm- 
Tablo 1. Dergi Listesi

\begin{tabular}{|c|c|c|c|c|c|}
\hline Source (Kaynak) & h_index & g_index & m_index & $T C^{*}$ & $N P^{*}$ \\
\hline Journal of Managerial Psychology & 16 & 28 & 1,14 & 807 & 37 \\
\hline Leadership and Org. Dev. Journal & 11 & 21 & 0,79 & 472 & 28 \\
\hline Journal of Applied Psychology & 20 & 22 & 0,43 & 28030 & 22 \\
\hline Organizational Research Methods & 16 & 20 & 0,73 & 5039 & 20 \\
\hline Personnel Review & 9 & 17 & 0,69 & 311 & 20 \\
\hline Employee Relations & 7 & 16 & 0,47 & 309 & 16 \\
\hline Personality And Individual Differences & 10 & 16 & 0,25 & 409 & 16 \\
\hline Career Development International & 8 & 14 & 0,53 & 216 & 15 \\
\hline Psychological Assessment & 8 & 12 & 0,33 & 622 & 12 \\
\hline Journal of Busıness And Psychology & 7 & 11 & 0,33 & 1406 & 11 \\
\hline Journal of Management Development & 6 & 10 & 0,43 & 109 & 11 \\
\hline Int. Journal of Productivity and Performance Management & 3 & 8 & 0,25 & 73 & 10 \\
\hline Management Decision & 6 & 10 & 0,50 & 173 & 10 \\
\hline Educational and Psychological Measurement & 5 & 9 & 0,09 & 454 & 9 \\
\hline European Journal of Marketing & 6 & 9 & 0,50 & 134 & 9 \\
\hline Int. Journal of Contemporary Hospitality Management & 8 & 9 & 0,73 & 225 & 9 \\
\hline Journal of Management & 7 & 9 & 0,19 & 8705 & 9 \\
\hline International Journal of Organizational Analysis & 2 & 4 & 0,13 & 26 & 8 \\
\hline Journal of Affective Disorders & 3 & 6 & 0,75 & 38 & 8 \\
\hline Journal of Personality & 5 & 8 & 0,26 & 220 & 8 \\
\hline
\end{tabular}

TC: Total citation(Toplam atıf). NP: Number of publications (Yayın sayısı).

lerinin toplandığı ortamdır (Podsakoff vd. 2003; MacKenzie ve Podsakoff 2012). Anket tekniği kullanılarak yapılan araştırmalarda veriler toplanırken yukarıdaki nedenleri ortadan kaldırmaya çalışmak OYY'nin oluşmasını engelleyebilir. Söz konusu etkenlere ilişkin ayrıntılı bilgilere, Tablo 2 'de yer verilmiştir.

\section{OYY'nin Kontrol Edilmesinde Prosedürel Çareler}

Sistematik hatayı kontrol altına almak amacıyla önerilen yollardan biri kullanılan bağımsız, aracı ve bağımlı değişkene ait verilerin farklı kaynaklardan toplanmasidır (Podsakoff vd. 2003; Podsakoff vd. 2012). Bu çözümün avantajı, kaynağın ya da katılımcının değiş̧kenlerin bağımlı ve bağımsız değişken arasındaki gözlemlenen ilişkiyi saptırmasını olanaksızlaştırmasıdır. Böylelikle katılımcıdan kaynaklanan tutarlılık motifleri, örtük teoriler, sosyal arzu edilebilirlik eğilimlerinin etkileri ortadan kalkabilir. Bağımsız değişkene ait veri katılımcıdan toplanırken, bağımlı değişkene ait verinin en az iki farklı (çalışanın amiri, çalışma arkadaşı, şirket kayıtları vb.) kaynaktan toplanması bir çözüm yolu olarak düşünülebilir. Verilerin farklı kaynaklardan toplanamadığ 1 durumlarda değişkenlere ait verinin farklı zamanlarda toplanması bir çözüm olarak değerlendirilmektedir (Podsakoff vd. 2003; Podsakoff vd. 2012). Verinin toplanmasında farklı zaman aralıklarının kullanılması (hafta, ay) araştırmada OYY riskini azaltabilmektedir.

Sistematik hatanın giderilmesi için başvurulan bir diğer çözüm ise değ isskenlere ait verinin farklı yöntem ve ortamda toplanmasıdır. Bazı araştırma- 
Tablo 2. OYY'nin Olası Nedenleri

\begin{tabular}{|c|c|}
\hline Potansiyel Neden & Tanımlama \\
\hline \multicolumn{2}{|l|}{$\begin{array}{l}\text { Ortak bir kaynak ve katılıma } \\
\text { tarafından üretilen yöntem } \\
\text { etkileri }\end{array}$} \\
\hline Tutarlılık motifi & Katılımcıların sorulara verdikleri cevaplarında tutarlılı̆ı korumaya çalışma eğilimidir. \\
\hline Gizli teoriler & $\begin{array}{l}\text { Katıımcıların belirli özellikler, davranışlar veya sonuçlar arasındaki ortak değişkenlik hakkındaki } \\
\text { inançlarıdır. }\end{array}$ \\
\hline Sosyal arzu & $\begin{array}{l}\text { Katılımcıların gerçek duygularından ziyade sosyal kabul edilebilirliklerinin bir sonucu olarak } \\
\text { ifadelere daha fazla cevap verme eğilimidir. }\end{array}$ \\
\hline Hoşgörü önyargısı & $\begin{array}{l}\text { Katıımcıların sosyal olarak arzu edilen özellikleri, tutumları veya davranışları tanıdıkları ve } \\
\text { sevmedikleri birinden daha çok sevdikleri birine atfetme eğilimidir. }\end{array}$ \\
\hline Kabullenme & Ankete katılanların ölçeğin içeriğinden bağımsız olarak ifadeleri kabul etme eğilimidir. \\
\hline $\begin{array}{l}\text { Pozitif veya negatif } \\
\text { duygulanma }\end{array}$ & $\begin{array}{l}\text { Katılımcıların kendilerini ve çevrelerindeki dünyayı genellikle olumsuz veya olumlu terimlerle } \\
\text { görme eğilimidir. }\end{array}$ \\
\hline Geçici ruh hali durumu & $\begin{array}{l}\text { Katılımcıların kendilerini ve çevrelerindeki dünyayı görme biçimini etkilemek için nispeten } \\
\text { yeni bir ruh hali uyandıran olayların etkisini ifade eder. }\end{array}$ \\
\hline \multicolumn{2}{|l|}{$\begin{array}{l}\text { Ifade özelliklerinin ürettiği } \\
\text { yöntem etkileri }\end{array}$} \\
\hline Ifadenin sosyal arzu edilirliği & $\begin{array}{l}\text { Ifadelerin daha sosyal olarak arzu edilen tutumları, davranışları veya algıları yansıtacak } \\
\text { şekilde yazılabileceğini ifade eder. }\end{array}$ \\
\hline İfadenin talep özellikleri & İfadelere nasıl yanıt verileceği konusunda gizli ipuçları iletebilmesidir. \\
\hline $\begin{array}{l}\text { Ifadenin karmaşıklığı veya } \\
\text { belirsizliği }\end{array}$ & $\begin{array}{l}\text { Belirsiz olan ifadelerin, katılımcıların kendi sezgisel özelliklerini kullanarak sistematik olarak } \\
\text { yanıt vermelerine veya rastgele yanıt vermelerine izin vermesi durumudur. }\end{array}$ \\
\hline $\begin{array}{l}\text { Ölçek formatı ve ölçek } \\
\text { ankorları }\end{array}$ & $\begin{array}{l}\text { Bir ankette aynı ölçek formatının (örneğin, Likert ölçekleri, semantik diferansiyel ölçekler, } \\
\text { yüz ölçekleri) kullanılmasıyla oluşan yapay kovaryansı ifade eder. }\end{array}$ \\
\hline Olumsuz ifadeler & Olumlu (olumsuz) ifadelerin kullanımının ölçek üzerinde yapay ilişkiler üretebilmesidir. \\
\hline \multicolumn{2}{|l|}{$\begin{array}{l}\text { Ifade ortamı (kapsamı, } \\
\text { bağlamı) tarafından üretilmiş } \\
\text { yöntem etkileri }\end{array}$} \\
\hline $\begin{array}{l}\text { Ifade ateşleme (çalıştırma, } \\
\text { hazırlama) etkileri }\end{array}$ & $\begin{array}{l}\text { Bağımlı ve bağımsız değişkeninin ölçekte konumlandırımasının, bu değişkeni ölçeği daha } \\
\text { belirgin hale getirebilmesi ve diğer değişkenlerle nedensel bir ilişki olduğu sonucuna } \\
\text { ulaşılmasıdır. }\end{array}$ \\
\hline Ifade gömme & $\begin{array}{l}\text { Olumlu ya da olumsuz ifadeler bağlamında gömülü olan tarafsız ifadelerin, bu öğelerin } \\
\text { değerlendirme özelliklerini almasıdır. }\end{array}$ \\
\hline Ortamın-uyardığı ruh hali & $\begin{array}{l}\text { Ölçekte karşılaşılan ilk soru (veya soru seti) ölçeğin geri kalanına yanıt vermek için bir ruh haline } \\
\text { neden olmasıdır. }\end{array}$ \\
\hline Ölçek uzunluğu & $\begin{array}{l}\text { Ölçeklerin daha az öğe varsa, önceki öğelere verilen yanıtların kısa süreli bellekte erişilebilir } \\
\text { olması ve diğer öğelere yanıt verirken hatırlanması daha olasıdır. }\end{array}$ \\
\hline $\begin{array}{l}\text { Ölçeklerdeki ifadeleri } \\
\text { birbirine karıştırarak yazma }\end{array}$ & $\begin{array}{l}\text { Birlikte gruplandırılan farklı yapılardan gelen öğelerin dış yapı korelasyonlarını azaltabilmesi } \\
\text { ve içyapı korelasyonlarını artırabilmesidir. }\end{array}$ \\
\hline \multicolumn{2}{|l|}{$\begin{array}{l}\text { Ölçme ortamı tarafından } \\
\text { ortaya çıkarılan yöntem etkisi }\end{array}$} \\
\hline Ölçme zamanı ve yeri & $\begin{array}{l}\text { Aynı zamanda ve yerde ölçülen farklı yapıların ölçümlerinin, yapıların içeriğinden bağımsız } \\
\text { olarak yapay kovaryans üretebilmesidir. }\end{array}$ \\
\hline $\begin{array}{l}\text { Ölçmeyi gerçekleştirmek } \\
\text { için kullanılan ortak araç } \\
\text { veya aracı }\end{array}$ & $\begin{array}{l}\text { Aynı ortamla ölçülen farklı yapıların ölçümlerinin yapıların içeriğinden bağımsız } \\
\text { olarak yapay kovaryans üretebilmesidir. }\end{array}$ \\
\hline
\end{tabular}

Kaynak: Podsakoff vd.nin (2003) çalışmasından uyarlanmıştır. 
cilar (Cronbach 1946; Campbell ve Fiske 1959; Feldman ve Lynch 1988; Podsakoff vd. 2003), OYY'nin ölçek özelliklerinden kaynaklanabileceğini gözlemlemiştir. Bu prosedürün avantajı, bazı ölçek formatlarının (örneğin, Likert), maddenin içeriğini veya maddenin diğer özelliklerini (örneğin, sayılarını değiştirmeden) başka biçimlere (örneğin, anlamsal diferansiyel) dönüştürmenin genellikle kolay olmasıdır. Ancak, ifadelerin içerik geçerliliğini korumaya öncelik vermek önemlidir (MacKenzie vd. 2011). Verinin farklı şartlarda toplanmasına katılımcının bulunduğu fiziksel ortamın değiştirilmesi örnek gösterilebilir. Örneğin bağımsız değişkene ait veri işyerinde, bağımlı değişkene ait veri farklı bir mekânda veya çalışanın evinde toplanabilir. Ancak bu durum katılımcı ve araştırmacı için fazladan zaman ve maliyet yaratabilmektedir.

Bağımsız ve bağımlı değişkenlere ait verilerin zamansal, mekânsal, psikolojik ve metodolojik farklılıklar yaratılarak toplanmasının sağladığı avantajlar vardır. Bu avantajlardan ilki hatırlamayı engelleyerek, bunun sonucunda ortaya ç1kan yanılmayı engellemesidir. Başka bir deyişle aynı mekân, aynı zaman, aynı psikolojik şartlar ve aynı metodolojik özelliklerin ortaya çıkaracağı bilgi hatırlama durumunu ortadan kaldırarak ortaya çıkması muhtemel OYY engellenebilir. İkincisi ise katılımcının bağımsız değişkene verdiği cevabı hatırlamasını veya hatırlama ve tutarlılık motivasyonunu azaltarak hatırlamada ortaya çıkacak yanlılık engellenebilir (Podsakoff vd. 2003; Podsakoff vd. 2012)

Ölçek sırasının dengelenmesi de sistematik hatayı azaltabilmektedir. Araştırmalarda genellikle önce bağımsız değişkenlere ait ifadeler yer almakta ve sonrasında bağımlı değişken ifadelerine yer verilmektedir. Bu anlayışın tersine ifade gruplarının yerlerinin değiştirilmesi katılımcılarda Tablo 1'de açıklanan ifade ateşleme ve ifade gömme etkilerini azaltabilmektedir. Ölçekte yer alan ifadelerin iyileştirilmesi OYY'i azaltmada kullanılan bir diğer yöntemdir (Podsakoff vd. 2003; Podsakoff vd. 2012). Ölçek uzunluklarının (5'li Likert ölçeği, 7'li Likert ölçeği gibi) düzenlenmesi de yöntem yanlılığını azaltabilmektedir. Ancak, orijinal ölçek uzunluklarını değiştirmek, araştırmada yapının anlamını değiştireceğinden önerilmemektedir. Ayrıca bu durum araştırmanın geçerliliğini tehlikeye atabilmektedir. Buraya kadar açılanan çözüm önerileri ve yöntemlere ek olarak MacKenzie ve Podsakoff (2012) kat1lımcıların ifadeleri cevaplarken belirli bir motivasyona ve cevaplandırmada belirli bir biliş düzeyine sahip olmaları gerektiğini ifade etmektedir (Podsakoff vd. 2003; Podsakoff vd. 2012).

\section{İstatistiksel Çözümler}

Deneysel araştırmalarda prosedürel çözümlerin yanı sıra sistematik hata varyansının bulgular üzerindeki potansiyel etkilerini kontrol etmek için istatistiksel çözüm yolları kullanılabilmektedir. Genel olarak kullanılan bu istatistiksel teknikler, avantaj ve dezavantajları aşağıda ayrıntılı olarak açıklanmıştır (Podsakoff vd. 2003):

1. Harman'ın tek faktör testi (Harman's single-factor test)

2. Kismi korelasyon prosedürü (Partial correlation procedure)

3. Ölçülmüş örtülü metotlar faktörü (Measured latent methods factor)

4. Ölçülmemiş örtülü metotlar faktörü (Unmeasured latent methods factor)

5. Çoklu metot faktörleri (Multiple methods factor)

6. Doğrulayıcı faktör analizi gösterge tekniği (CFA marker technique)

Harman'ın tek faktörlü testi: OYY sorununu ele almak için araştırmacılar tarafından en yaygın kullanilan tekniklerden biridir. Geleneksel olarak, bu tekniği kullanan araştırmacılar, çalışmalarındaki tüm değişkenleri keşfedici faktör analizine yüklerler (Aulakh ve Gencturk 2000).

Kısmi korelasyon prosedürü: Metot varyansının etkilerini kontrol etmek için kullanılan bir diğer istatistiksel tekniktir. Katılımcılar için sıklıkla sistematik hata varyansına neden olduğu varsayılan iki değişken, katılımcıların duygusal durumları ve sosyal olarak arzulanan şekilde cevap verme eğilimidir. Bu gerekçe ile araştırmacılar değişkenleri doğrudan ölçerek yanlılığ etmeye çalışır (Jex ve Spector 1996). 
Tablo 3. İncelenen Turizm Makalelerinde OYY Yöntemlerinin Kullanımı

\begin{tabular}{|c|c|c|c|c|c|c|c|c|c|c|c|c|c|c|c|c|c|c|c|c|c|}
\hline $\begin{array}{l}\text { Kodlar } \\
\text { Kategoriler }\end{array}$ & 1 & 2 & 3 & 4 & 5 & 6 & 7 & 8 & 9 & 10 & 11 & 12 & 13 & 14 & 15 & 16 & 17 & 18 & 19 & $f$ & $\%$ \\
\hline \multicolumn{22}{|l|}{ Prosedürel Çözümler } \\
\hline $\begin{array}{l}\text { Verilerin Farklı } \\
\text { Kaynaklardan } \\
\text { Toplanması }\end{array}$ & & & & v & & & & & & & & & & & & v & & & & 2 & 7 \\
\hline Zamansal Ayırma & v & $v$ & & & & V & & & v & & & & & & & & & & & 4 & 13 \\
\hline Psikolojik Ayırma & & $v$ & & & & & & & & & & & & & & & $v$ & & & 2 & 7 \\
\hline Metodolojik Ayırma & & & & & & & & & & & & & & & & & & & v & 1 & 3 \\
\hline Diğer Teknikler & & $v$ & & & & & & $v$ & & & v & & & $v$ & $v$ & & & $v$ & & 6 & 20 \\
\hline \multicolumn{22}{|l|}{ istatistiksel Çözümler } \\
\hline $\begin{array}{l}\text { Harman'ın tek faktör } \\
\text { testi }\end{array}$ & $v$ & $\mathrm{~V}$ & $\mathrm{~V}$ & & $\mathrm{~V}$ & & & & $\mathrm{~V}$ & V & & V & v & & $v$ & & $\checkmark$ & & 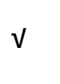 & 11 & 37 \\
\hline $\begin{array}{l}\text { Kısmi korelasyon } \\
\text { prosedürü }\end{array}$ & & & & & & & & & & & & & & & & & & & & 0 & 0 \\
\hline $\begin{array}{l}\text { Ölçülmüş örtülü } \\
\text { metotlar faktörü }\end{array}$ & & & & & & & & & & & & & & & & & & & & 0 & 0 \\
\hline $\begin{array}{l}\text { Ölçülmemiş örtülü } \\
\text { metotlar faktörü }\end{array}$ & & & & & & $\sqrt{ }$ & 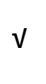 & & & & & & & & & & & v & & 3 & 10 \\
\hline $\begin{array}{l}\text { Çoklu metot } \\
\text { faktörleri }\end{array}$ & & & & & & & & & & & & & & & & & & & & 0 & 0 \\
\hline DFA gösterge tekniği & & $v$ & & & & & & & & & & & & & & & & & & 1 & 3 \\
\hline
\end{tabular}

Kodlar:

1: Karatepe vd. (2009) 2: Paek vd. (2015) 3: Karatepe (2010) 4: Klidas vd. (2007) 5: Karatepe (2011) 6: Min vd. (2016) 7: Gould vd. (2011) 8: Qin vd. (2014) 9: Lee vd. (2014)10: Ferreira vd. (2017) 11: Cheng vd. (2017)12: Karatepe vd. (2011) 13: Ting vd. (2016) 14: Pavlatos (2015) 15: Luo vd. (2017) 16: Ferrer-Rosell vd. (2017) 17: Cheraghalizadeh ve Tümer (2017) 18: Huang vd. (2019) 19: Uludağ (2016)

Ölçülmüş örtülü metotlar faktörü: Bu tekniği geliştiren araştırmacılar, gizli değişken modellerin kullanımına yönelmişlerdir. Tekniğin amacı, OYY nedeni doğrudan ölçülmek için, gizli bir yapı olarak modellemesini ve ilgili yapıların göstergelerinin buna yüklenmesini içerir (Podsakoff vd. 2003).

Ölçülmemiş örtülü metotlar faktörü: Kullanılan başka bir gizli değişken yaklaşımı, araştırmacının teorik modeline birinci dereceden ölçülmemiş bir latent (örtülü) değişken eklemesidir (Carlson ve Kacmar 2000).

Çoklu metot faktörleri: Bu teknik, daha önce açıklanan tekniklerden farklıdır. İlk olarak, yaklaşım- da birden çok birinci dereceden yöntem faktörü eklenebilmektedir. İkincisi, bu yöntem faktörlerinin her biri, yalnızca bir alt ifade kümesini etkilemek için kullanılmaktadır (Campbell ve Fiske 1959). Dolayısıyla, belirli bir ölçüme verilen cevapların varyansı, sistematik hata bileşenleri ayrılabilmekte, böylelikle araştırmacının değişkenler arasındaki ilişkileri kontrol ederken metot varyansı ile rastgele hata kontrolünü aynı anda yapmasına izin vermektedir.

Doğrulayıcı faktör analizi gösterge tekniğgi: Williams vd. (2010), örtülü metot faktörünün göstergeleri olarak, ölçüm özelliklerini ilgilendiren önemli değişkenlerle paylaşan bir dizi işaretle- 
yici değişkeninin kullanılmasını önermektedir. $\mathrm{Bu}$ tekniğin araştırmalarda uygulanması üç aşamadan oluşmaktadır. İlk aşamada, teknik gizli işaretleyici değişkeni ile ilişkili metot etkilerinin varlığ1 ve kuvveti test edilir. Bu tekniğin kullanıldığı modelin uyumunun temel modelin uyumuyla karşılaştırılması, OYY'nin temel göstergeleri üzerinde eşit etkilere sahip olduğu varsayımının bir testini sağlar. İkinci aşamada, metot varyansının temel modelin güvenilirliğini nasıl etkilediği ölçümlenir. Son olarak, üçüncü aşamada araştırma bulgularının güvenirliğini artırmaya yönelik bir duyarlılık analizi yapmak için kullanılır.

\section{İncelenen Turizm Makalelerinde OYY Yöntemlerinin Kullanımı}

Çalışmada, OYY'yi kontrol etmek için sözü edilen prosedürel ve istatistik çözümler dikkate alınarak oluşturulan ölçüt seti ile 1534 çalışmanın içerisinde turizm dergilerinde yayımlanan 19 çalışma değerlendirilmiştir. Böylece bu dergilerde yayımlanan çalışmalarda OYY konusundaki farkındalık ve mevcut durum analiz edilmiştir (Tablo 3).

\section{SONUÇ VE ÖNERILER}

$\mathrm{Bu}$ çalışmada sistematik yazın taraması ile OYY'nin ne olduğunu, önemi, olası nedenlerini ve yanlılığı kontrol etmenin yolları açıklanmıştır. Sonrasında turizm dergilerinde yayımlanan ve anahtar kelimelerinde, başlıkta ve özetlerinde OYY geçen çalışmalarda mevcut durum analiz edilmiştir. Çalışma bulgularına göre prosedürel çözümlerden en sık kullanılanının zamansal ayırma olduğu görülmektedir. Diğer taraftan, istatistiksel çözümlerden en sık kullanılanı ise Harman'ın tek faktörlü testidir. Harman'ın tek faktörlü testinin ortak yöntem varyansına duyarsız olduğu yönündeki eleştirilere rağmen (MacKenzi ve Podsakoff 2012; Podsakoff vd. 2012) bu teknik turizm dergilerinde araştırmacılar tarafından sıklıkla kullanılan bir tekniktir. Ölçülmemiş örtülü metotlar faktörü ikinci sırada kullanılan teknik olarak gözükmektedir. İncelenen 19 çalışmada OYY'yi kontrol altına alma ve test etme yöntemleri, seçilen çalışma tasarımına ve analizi- ne bağlı olarak farklılık göstermektedir. Min vd. (2016) az sayıda bağımsız değişkenli modellerde OYY'ye daha fazla dikkat edilmesi gerektiğini vurgulamaktadır. Bu durumda hem prosedürel önlemler hem de istatistiksel kontrollerin kullanılması şiddetle tavsiye edilmektedir.

Bu çalışmanın sonuçları, bazı kısıtlar ışığında yorumlanabilir. Çalışmada, uluslararası turizm dergilerinde İngilizce yazılmış, anahtar kelimelerinde, başlıklarında ve özetlerinde OYY ya da OYV kelimeleri geçen makalelerin içeriği incelenmiştir. Çalışma turizm araştırmalarında ortak yöntem yanlılığının nasıl ele alınacağı ile ilgili yol ve yöntemleri ulusal turizm yazınına tanıtmaktadır. Turizm araştırmacıları ilgili alan yazının öngördüğü yol ve yöntemlerden en uygun olanı veya olanları seçerek, OYY'yi en aza indirebilir ve araştırma sonuçlarının geçerliliği ve güvenilirliğini artırabilirler. Bunun ötesinde, araştırmacılar bu çalışmada belirlenen OYY ile ilgili ölçüt setini kullanarak ulusal turizm yazınındaki konu ile ilgili durumun tespitini yapabilirler.

\section{KAYNAKÇA}

Aria, M. ve Cuccurullo, C. (2017). Bibliometrix: An R-tool for Comprehensive Science Mapping Analysis, Journal of Informetrics, 11 (4): 959-975.

Aulakh, P. S. ve Gencturk, E. F. (2000). International Principal-Agent Relationships: Control, Governance and Performance, Industrial Marketing Management, 29 (6): 521-538.

Bagozzi, R. P. ve Yi, Y. (1990). Multi Trait-Multi Method Matrices in Consumer Research, Journal of Consumer Research, 17 (4): 426-439.

Campbell, D. T. ve Fiske, D. W. (1959). Convergent and Discriminant Validation by the Multi Trait-Multi Method Matrix, Psychological Bulletin, 56 (2): 81-105.

Carlson, D. S. ve Kacmar, K. M. (2000). Work-Family Conflict in the Organization: Do Life Role Values Make a Difference?, Journal of Management, 26 (5): 1031-1054.

Cheng, J. C. ve Chen, C. Y. (2017). Job Resourcefulness, Work Engagement and Prosocial Service Behaviors in the Hospitality Industry, International Journal of Contemporary Hospitality Management, 29 (10): 2668-2687.

Cheraghalizadeh, R. ve Tümer, M. (2017). The Effect of Applied Resources on Competitive Advantage in Hotels: Mediation and Moderation Analysis, Journal of Hospitality and Tourism Management, 31 : 265-272.

Conway, J. M. ve Lance, C. E. (2010). What Reviewers Should Expect from Authors Regarding Common Method Bias in Organizational Research, Journal of Business and Psychology, 25 (3): 325-334. 
Cronbach, L. J. (1946). Responsesets and Test Validity, Educational and Psychological Measurement, 6 (4): 475-494.

Feldman, J.M. ve Lynch, J.G. (1988). Self-Generated Validity and Other Effects of Measurement on Belief, Attitude, Intention, and Behavior, Journal of Applied Psychology, 73 (3): 421-35.

Ferreira, A. I., Martinez, L. F., Lamelas, J. P. ve Rodrigues, R. I. (2017). Mediation of Job Embeddedness and Satisfaction in the Relationship between Task Characteristics and Turnover: A Multi Level Study in Portuguese Hotels, International Journal of Contemporary Hospitality Management, 29 (1): 248-267.

Ferreira, F. A. (2018). Mapping the Field of Arts-Based Management: Bibliographic Coupling and Co-Citation Analyses, Journal of Business Research, 85: 348-357.

Ferrer-Rosell, B., Coenders, G. ve Marine-Roig, E. (2017). Is Planning Through the Internet (Un)Related to Trip Satisfaction?, Information Technology \& Tourism, 17 (2): 229-244.

Gould, J., Moore, D., Karlin, N. J., Gaede, D. B., Walker, J. ve Dotterweich, A. R. (2011). Measuring Serious Leisure in Chess: Model Confirmation and Method Bias, Leisure Sciences, 33 (4): 332-340.

Huang, Y. C., Chang, L. L. ve Backman, K. F. (2019). Detecting Common Method Bias in Predicting Creative Tourists Behavioural Intention with an Illustration of Theory of Planned Behaviour, Current Issues in Tourism, 22 (3): 307-329.

Jex, S. M. ve Spector, P. E. (1996). The Impact of Negative Affectivity on Stress or Strain Relations: A Replication and Extension, Work and Stress, 10 (1): 36-45.

Karatepe, O. M. (2010). The Effect Of Positive And Negative Work-Family Interaction on Exhaustion: Does Work Social Support Make a Difference? International Journal of Contemporary Hospitality Management, 22 (6): 836-856.

Karatepe, O. M. (2011). Do Job Resources Moderate the Effect of Emotional Dissonance on Burn Out? A Study in the City of Ankara, Turkey, International Journal of Contemporary Hospitality Management, 23 (1): 44-65.

Karatepe, O. M. ve Zargar Tizabi, L. (2011). Work-Related Depression in the Hotel Industry: A Study in the United Arab Emirates, International Journal of Contemporary Hospitality Management, 23 (5): 608-623.

Karatepe, O. M., Yorganci, I. ve Haktanir, M. (2009). Outcomes of Customer Verbal Aggression Among Hotel Employees, International Journal of Contemporary Hospitality Management, 21 (6): 713-733.

Klidas, A., Van Den Berg, P. T. ve Wilderom, C. P. (2007). Managing Employee Empowerment in Luxury Hotels in Europe, International Journal of Service Industry Management, 18 (1): 70-88.

Lance, C. E., Dawson, B., Birkelbach, D. ve Hoffman, B. J. (2010). Method Effects, Measurement Error, and Substantive Conclusions, Organizational Research Methods, 13 (3): 435-455.

Lee, J. S., Lee, C. K. ve Park, C. K. (2014). Developing and Validating a Multi Dimensional Quality Scale for MegaEvents, International Journal of Hospitality Management, 43: 121-131.
Luo, Z., Marnburg, E. ve Law, R. (2017). Linking Leadership and Justice to Organizational Commitment: The Mediating Role of Collective Identity in the Hotel Industry, International Journal of Contemporary Hospitality Management, 29 (4): 1167-1184.

MacKenzie, S. B. ve Podsakoff, P. M. (2012). Common Method Bias in Marketing: Causes, Mechanisms, and Procedural Remedies, Journal of Retailing, 88 (4): 542-555.

Min, H., Park, J. ve Kim, H. J. (2016). Common Method Bias in Hospitality Research: A Critical Review of Literature and an Empirical Study, International Journal of Hospitality Management, 56: 126-135.

Paek, S., Schuckert, M., Kim, T. T. ve Lee, G. (2015). Why is Hospitality Employees' Psychological Capital Important? The Effects of Psychological Capital on Work Engagement and Employee Morale, International Journal of Hospitality Management, 50: 9-26.

Pavlatos, O. (2015). An Empirical Investigation of Strategic Management Accounting in Hotels, International Journal of Contemporary Hospitality Management, 27 (5): 756767.

Podsakoff, P. M., MacKenzie, S. B. ve Podsakoff, N. P. (2012). Sources of Method Bias in Social Science Research and Recommendations on How to Control it, Annual Review of Psychology, 63: 539-569.

Podsakoff, P.M., MacKenzie, S.B., Lee, J.-Y. ve Podsakoff, N.P. (2003). Common Method Biases in Behavioral Research: A Critical Review of the Literature and Recommended Remedies, Journal of Applied Psychology, 88 (5): 879-903.

Podsakoff, P.M. ve Organ, D.W. (1986). Self-Reports in Organizational Research-Problems and Prospects, Journal of Management, 12 (4): 531-44.

Qin, Q., Wen, B., Ling, Q., Zhou, S. ve Tong, M. (2014). How and When the Effect of Ethical Leadership Occurs? A Multi Level Analysis in the Chinese Hospitality Industry, International Journal of Contemporary Hospitality Management, 26 (6): 974-1001.

Richardson, H. A., Simmering, M. J. ve Sturman, M. C. (2009). A Tale of Three Perspectives: Examining Post Hoc Statistical Techniques for Detection and Correction of Common Method Variance, Organizational Research Methods, 12 (4): 762-800.

Spector, P. E. (2006). Method Variance in Organizational Research: Truth or Urban Legend?, Organizational Research Methods, 9 (2): 221-232.

Ting, H., Run, E. C., Cheah, J. H. ve Chuah, F. (2016). Food Neophobia and Ethnic Food Consumption Intention: An Extension of the Theory of Planned Behaviour, British Food Journal, 118 (11): 2781-2797.

Uludağ, O. (2016). The Mediating Role of Positive Affectivity on Testing the Relationship of Engagement to Academic Achievement: an Empirical Investigation of Tourism Students, Journal of Teaching in Travel \& Tourism, 16 (3): 163-177.

Van Eck, N.J. ve Waltman, L. (2010). Software Survey: VOSviewer, a Computer Program for Bibliometric Mapping, Scientometrics, 84 (2): 523-538. 

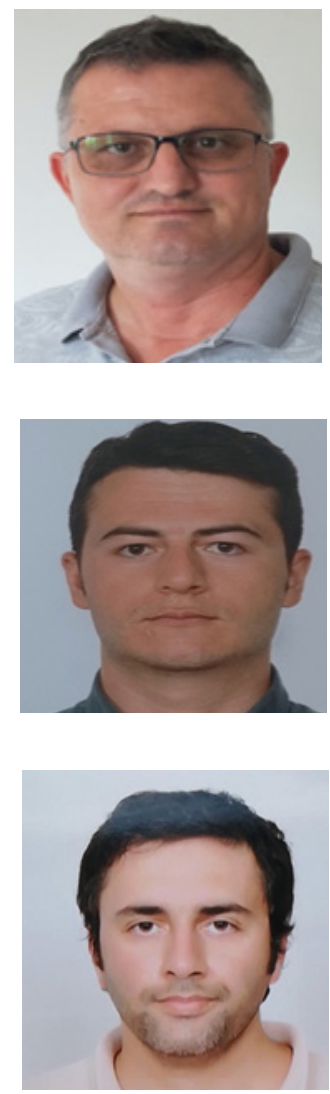

\section{Beykan ÇIZEL}

Ihsan Doğramacı Bilkent Üniversitesi, Turizm ve Otel Işletmeciliği Bölümü’nden mezun oldu (1996). Yüksek lisans derecesini Akdeniz Üniversitesi'nden Turizm ve Otelcilik Dalı'ndan (1999), doktora derecesini de Akdeniz Üniversitesi'nde İşletme Dalı'ndan aldı (2005). Akdeniz Üniversitesi'nde çalışmaya başladı (1996). Doçentlik unvanını ise İşletme Bölümü Yönetim ve Organizasyon Ana Bilim Dalı'ndan aldı (2010). Halen Akdeniz Üniversitesi Turizm Fakültesi'nde profesör olarak görev yapmaktadır. Temel çalışma alanları, turizm ve otel işletmeciliği, sosyal psikoloji ve e-turist davranışıdır.

\section{Onur SELÇUK}

Anadolu Üniversitesi, Turizm Fakültesi'nden, Turizm ve Otel İşletmeciliği Bölümü’nden mezun oldu (2015). Yüksek lisans derecesini Anadolu Üniversitesi'nden Turizm İşletmeciliği Dalı'ndan (2018) aldı. Doktora eğitimine Akdeniz Üniversitesi, Turizm İşletmeciliği Dalı'nda başladı (2019). Akdeniz Üniversitesi'nde çalışmaya başladı (2018). Halen Akdeniz Üniversitesi Turizm Fakültesi'nde görev yapmaktadır. Temel çalışma alanları, turizm ve otel işletmeciliği, sanat tarihi, beşeri coğrafyadır.

\section{Eniser ATABAY}

Akdeniz Üniversitesi Turizm ve Otel İşletmeciliği Yüksekokulu'ndan, Konaklama İşletmeciliği Bölümü’nden mezun oldu (2013). Yüksek lisans derecesini Akdeniz Üniversitesi'nden Turizm ve Otelcilik Dalı'ndan aldı (2019). Doktora eğitimine Akdeniz Üniversitesi, Turizm İşletmeciliği Dalı'nda başladı (2019) Haliç Üniversitesi'nde çalışmaya başladı (2016). Ardından Akdeniz Üniversitesi'nde çalışmaya başladı (2016). Halen Akdeniz Üniversitesi, Göynük Mutfak Sanatları Meslek Yüksekokulu'nda görev yapmaktadır. Temel çalışma alanları, turist davranışı, e-pazarlama, e-turizmdir. 